\title{
The Negotiation of Meaning in Epistemic Situations
}

\author{
Michael J. Baker ${ }^{1}$
}

Published online: 9 June 2015

(C) International Artificial Intelligence in Education Society 2015

\begin{abstract}
This article is a commentary on a model for negotiation in teaching-learning dialogues (Baker 1994) that traces its origins and developments over the past 20 years. The first main section of the paper describes the research background out of which the model arose, within the credo of individualised tutoring of the 1980s. This is followed by a summary of the main elements of the model, then a presentation of its subsequent developments. These comprise the analysis of argumentation dialogue and its potential for collaborative learning, the analysis of interpersonal relations in relation to the interactive regulation of affect, and extensions of the model to other epistemic situations such as explanation generation, co-design, online epistemic discussions and use of communication interfaces in computer-supported collaborative learning environments. On these bases, the object of study of this research is defined as the processes of negotiation of meaning in epistemic situations. It is concluded that the main core of the model was retained, throughout its deepening and extension, but the underlying theory was radically changed, from cognitivist belief-systems to a view of dialogue itself as collective thinking. Two challenges for artificial intelligence and education research are raised: the formalisation of interpersonal relations as they are played out in social interaction, and the analysis of the processes of appropriation of discourse genres.
\end{abstract}

Keywords Dialogue $\cdot$ Collaborative learning - Argumentation · Computer supported collaborative learning $\cdot$ Scripted interaction $\cdot$ Intelligent tutoring systems

\section{Introduction}

This article is a commentary on a paper that I published a little over 20 years ago, entitled "A Model for Negotiation in Teaching-learning Dialogues" (Baker 1994), in the International Journal of Artificial Intelligence and Education. I reflect on the

Michael J. Baker

michael.baker@telecom-paristech.fr

1 Centre National de la Recherche Scientifique \& Telecom ParisTech, Paris, France 
intellectual background out of which that research emerged, describe its further developments up to the present, and give some pointers for future research.

A few words as to why I think such an enterprise may be of interest to people other than myself are perhaps in order.

Firstly, no social group can really advance without some shared sense of its own history, fairly stated and collectively constructed. And the same is true, I would say, of research fields, especially those that bear on the study of people, considered as social beings. Without such a history, mistakes of the past can be made again, past achievements can be overlooked, leading to wasteful exploration or reduplication of effort; and researchers in a given field may lack a well-founded sense of where they are heading. What I have to say represents only a small slice of such a recent history of the domain of Artificial Intelligence and Education research: it is in no sense an attempt to produce a complete recent history. But the general tendencies that this 'slice' of scientific history touches upon, relating to modelling dialogues in learning situations, may nevertheless reach further than the specific research concerned.

Secondly, research on the use of technology in education - of which Artificial Intelligence and Education research could be seen to be a part, although it can also be seen as a branch of computer science - is particularly prone to the neglect of history. This might be due to two reasons. On one hand, new researchers from every discipline - not only education and computer science, but also chemistry, biology, literature, linguistics, and so on - come into this field all the time, since most are also, in their professional capacities, concerned with teaching. Therefore, it might not be widely known in 2015 that this field has at least 40 years of history. Its beginnings could be dated from, at the latest, the report on "Intelligent CAI" of Collins and Grignetti (1975). A little - albeit very restricted - history may therefore be useful. Furthermore, the early research of Collins and colleagues just cited, on what came to be known as "Socratic tutoring", relates to that described here, since both relate to modelling dialogues in educational situations. On the other hand, technological change also continually brings new researchers into this field, as engineers and "users" almost inevitably come round to considering uses of their innovative technologies in the field of education. That may lead to the belief that results obtained during the early 1990s, with respect to, for example, direct manipulation interfaces, are not relevant to the study of the use of smartphones in the 21 st century. This may or may not be so. But this highlights a difficulty faced by all research on the use of technological artefacts, which is to generalise results beyond the specific characteristics of the technologies of the day.

\section{Background}

"A model for negotiation in teaching-learning dialogues" (henceforth abbreviated to "the paper", "my paper", or "NTD”) was published in 1994, around 4 years after I finished my $\mathrm{PhD}$ in cognitive science, from the Open University (UK), my research having begun in 1986 under the supervision of Dr. Mark Elsom-Cook in the Centre for Information Technology in Education (CITE), directed by Prof. Tim O'Shea. Awaiting publication in 1994, the ideas in NTD were presented in an invited speaker talk at the AI-ED 1993 conference (Baker 1993) in Edinburgh. 
My research grew out of a particular "spirit of the age", or "system of ideas" (ideology) in the domain (that was called "AI and ED(ucation)", or "ITS: Intelligent Tutoring Systems" in the 1980s), having as a background the seminal collection of articles published 4 years before I began to enter the field, edited by Sleeman and Brown (1982).

In the 1980s, the unquestioned credo ("I believe") of Artificial Intelligence and Education research was to provide individualised tutoring, in the form of Intelligent Tutoring Systems. The aim was to model individual students' knowledge in specific domains, and thereby provide teaching that was adapted in its content and mode of presentation. Historians of science will be able to describe the socio-economic forces behind the emergence of precisely that aim. But Skinner (1961), decades before, had already announced a research programme according to which his teaching machines would enable each student to progress at his or her own rhythm: provided, of course, that they gave the right responses. Cognitivism of the AI kind took on this behaviourist vision, despite its aim of getting at the cognitions 'behind' behaviour. It must also be remembered that the 1980 s was a period before the widespread use of Internet, and the now common emphasis on the study of collaboration in co-located or distant groups and teams. I shall return to that "collaborative revolution" below.

But ideologies — including scientific ones — are often defined by what they are against, just as much as by what they propose. The antitheses of the $1980 \mathrm{~s}$ credo were, firstly, the so-called transmission model of education (even though it is hard to find an explicit statement espousing such a view in the literature); and secondly, the purported (over-)emphasis in the field on studying teaching and learning in already formalised domains, such as mathematics and computer science (well known to computer scientists ...). And there was supposed to be a crucial link between the two, given that, to the extent that a domain is formalised, with known normatively correct procedures and problem solutions, this would encourage — or at the very least allow - a teaching model that consists essentially in transmitting, communicating or more generally inculcating such correct answers into the student. In intelligent tutoring systems, this model could take the form of the system producing an overall plan for how the dialogue would proceed to achieve the system's tutoring goals, with the students' interventions being essentially framed by that plan.

So the first step within the "knowledge negotiation" approach (see the collection of articles in Moyse and Elsom-Cook 1992), of which NTD was a part, was to insist on the study of more 'open' teaching domains, such as history and, in my own case, musical analysis (Baker 1989a). In such domains, certain knowledge, to be transmitted, is simply not the norm. Rather, in those domains, there usually exists a diversity of viewpoints on intrinsically negotiable knowledge, with respect to which people need to argue in order to reach a shared viewpoint. With respect to research on intelligent tutoring systems, the proposal was therefore to give primacy to tutorial dialogue models, whose requirements would determine what knowledge representation was appropriate to them, rather than the other way round. Thus, for example, the negotiative and argumentative character of "knowledge negotiation" dialogue models would require a knowledge representation comprising alternative viewpoints, and systems of justified beliefs. And that was what the KANT system (Kritical Argument Negotiated Tutoring system), developed as a prototype during my PhD (Baker 1989b), tried to do, i.e., to engage in a negotiative and argumentative dialogue with a student user, with 
respect to problem solutions (in this case, about musical structure analysis) and their justifications. NTD was essentially a further formalisation of my $\mathrm{PhD}$ research, extended towards the analysis of collaborative problem-solving situations.

\section{Elements of the Model}

The NTD model comprised, firstly, a representation of initial and final states of negotiation, which were basically that the set of agents share the goal of reaching agreement on a set of "negotia", whose nature is not defined at the outset. "Negotia" are the objects of negotiation, the things that can be negotiated. Although the model proposed several types of negotia, on the task and communication levels, NTD focussed on the former. The basic underlying idea was that, in negotiation, parties make "offers" (of negotia), — such as "the sale price should be $1000 €$ ", or "the problem solution is $\mathrm{p} 1$ " - that can be successively refined (e.g., "1000€, provided you add in xyz", or "p1 provided that p2") in order to reach agreement with respect to them. Furthermore, (counter-)arguments can be provided with respect to specific refinements of proposals, in the attempt to persuade or convince agents to agree to them.

Secondly, three specific negotiation processes, or strategies, were proposed, as a means for reaching a state of agreement: refine, stand pat, and argue. It turned out that in the paper, detailed consideration of the refine strategy alone was sufficient to fill up more than 50 pages of published text. So details of the argue strategy were deferred to later work (as became the case: see below). Additionally, the stand pat strategy was conceived as a type of asymmetrical version of the refine strategy. It basically meant that a single agent was invited to successively refine its initial proposal, with others waiting, or "standing pat", giving positive or negative feedback on successive refinements of the offer until they (possibly) agreed to it. In sum, NTD was concerned solely with knowledge refinement processes in negotiation; and the title of article should therefore have been "Elements of a model for knowledge negotiation ..." (or else, the "Towards a model for ..." type of title, that was quite popular in that period).

The refine strategy was defined in terms of two main elements: communicative acts of negotiation, and transformation functions. What is important about the communicative acts is that, in accordance with the knowledge negotiation approach, they are "proposals", with concomitant "acceptances" or "rejections", and not "assertions". This has the important consequence that in such dialogues, participants are not expressing their beliefs (underlying their assertions), but rather what they are (not) willing to accept (Cohen 1992). Acceptance is seen as a type of policy for joint reasoning, of a conditional nature: I will accept $\mathrm{p}$ if you will accept $\mathrm{p}$. This changes significantly the way that students' problem-solving dialogues are to be seen, and restates the problem of collaborative learning to be that of understanding the relations between acceptance in dialogue, and what students believe. But this reformulation of the problem of learning in and by dialogue can be taken even further (see the "Paradigm Shift" section below), to call into question the very meaning of the question: "but what do students 'really" think?" (cf. Edwards 1993). The implications for AI and ED research, of following through the calling into question of the very point of attempting to identify students' beliefs 'behind' their interactions with the system, would be quite profound. What, in fact, are we analysing, when we automatically attempt to 'infer' something about 
students, on the basis of traces of their manifest behaviours? What are the epistemological and ontological statuses of what is analysed?

To return to elements of the NTD model and the refine strategy, transformation functions represent, basically, the ways in which one interlocutor can transform the utterance or the propositional content proposed by another. Such transformation functions are of four main types: "expansion" (e.g., adding a proposition or predicate, making an inference, generalising), "contraction" (the reverse of expansion), "neutral" (e.g., linguistically reformulating or repeating the proposal) and "foundational" (explanation, justification, argument). Note that foundational transformations become arguments only in the case of explicit disagreement. A significant section of the paper was devoted to exploring the contextual effects of specific transformation functions, and sequences of proposals, with respect to expression of (non-)acceptance, on the communicative act level. For example, if one agent proposes the explanation "the energy", and another replies, transforming this proposal, by "the kinetic energy", this implies a partial acceptance/rejection of the first proposal, that could be glossed as "I accept that it is 'the energy' that explains the behaviour, provided that you accept, more specifically, that it is the 'kinetic energy' that is involved'. In subsequent work, relations between these dialogic transformation functions and Michalski's (1993) "knowledge transmutations", described in machine learning research, were explored (MephuNguifo et al. 1999).

In summary, the paper described the key elements of a model for sustaining negotiative teaching dialogues, between a computer tutor and a human user/learner, focussing on how proposals on the knowledge level can be mutually refined in order to achieve agreement, using specific types of communicative acts, that indirectly realise transformation functions. The shift from the expression of assertions by the teacher, to be acquired by the learner, towards negotiation of topics to be discussed, as well as the very nature of knowledge itself, had the consequence of decoupling what was said in dialogue (attitudes, such as acceptance) from students' more deep-seated beliefs. This restated and left open the question of how and when jointly refined ideas are appropriated by individuals, beyond a specific dialogue.

\section{Developments}

In a sense, it is quite simple for me to describe the subsequent developments of the research initiated in the NTD paper, since it provided a general framework that I have deepened and extended over the past 20 years. As stated above, the model focussed exclusively on negotiation on the knowledge level, and on a single strategy (mutual refinement). Over the 20 years that have followed publication of the paper, I have worked on completing and deepening that model, especially in terms of analysis of argumentation dialogue in learning situations, and negotiation on the level of the mutual regulation of interpersonal relations and affects. I also extended the empirical basis of the model, focussing on collaborative learning, rather than tutorial dialogues, as well as extending analysis beyond educational situations, to other 'epistemic' domains (co-design and creativity). In technological terms, I moved away from human-machine dialogue modelling, to apply the model to design and evaluation of uses of ComputerSupported Collaborative Learning (CSCL) communication and co-working interfaces. 
I shall briefly mention some of these developments below. But before doing that, I would like to make a few general remarks about scientific changes in cognitive science as a whole (I see Artificial Intelligence and Education research as that part of cognitive science which is focussed on technologically mediated educational processes ${ }^{1}$ ) over the last 20 years, that greatly influenced the way I extended the research published in the NTD paper.

\section{Paradigm Shift}

To state the matter simply, during the 1980s, the nature of the collaboration between computer scientists and social scientists (working mostly in educational psychology and cognitive psychology of learning) within Artificial Intelligence and Education research was close and quite straightforward, since the fundamental models of human cognition, and learning were basically shared (Symbolic Information Processing, or "SIP"), although psychological validity, computational validity and educational utility were of course distinguished. Then, at the beginning of the 1990s, the "situated cognition/learning debate" occurred (see Cognitive Science 17, 1993); distributed cognition, cultural-historical activity, discursive psychology, and other critical approaches came to the fore, that basically rejected the SIP model on which the previous marriage between computational and social sciences in AI and Education had been based. In addition - again, very briefly and schematically - at the beginning of the 1990s, more widespread use of Internet was emerging, and, for many, this shifted the focus of research, towards the study of computer-mediated communication in groups of learners, rather than one-to-one machine-teacher-individual-student dialogues. Artificial Intelligence and Education research adapted to these changes, applying its accumulated knowledge to problems such as intelligent configuration of groups on the basis of student models (e.g., Hoppe 1995). But for many educationalists and psychologists (those — by no means all — who had adapted to the paradigm shift), this changed their role in the field of AI and Education, from co-modellers of cognitive processes towards co-designers and evaluators of learning gains resulting from use of Intelligent Tutoring Systems. Not all educationalists and psychologists welcomed this change of role.

My own shift towards the study of collaborative learning, with an alternative theoretical-methodological framework to that proposed by SIP, took place during these paradigm changes, but was motivated by personal and empirical experience rather being the result of 'theoretical conversion'. In the year following publication of NTD, I tried to apply its theoretical model to the analysis of knowledge co-construction on the basis of a transcription of a collaborative problem solving dialogue (in physics) involving two students, lasting around $40 \mathrm{~min}$ (that implies around 30 pages of text, for a basic transcription of simply the verbal elements, excluding non-verbal communication and gesture). ${ }^{2}$ My (extremely ambitious) aim was to develop an empiricallygrounded "Beliefs, Desires, Intentions" formal model of communication in dialogue, that would be predictive with respect to potential knowledge co-elaboration processes, as well as possibilities for resolving verbal conflicts of opinion by argumentation, given

\footnotetext{
${ }^{1}$ Cf. John Self's (1992) project for the elaboration of a general "computational mathetics".

${ }^{2}$ Andrée Tiberghien is to be thanked (or blamed?) for having provided me with this transcription.
} 
input on (amongst other things) students' initilal knowledge states. ${ }^{3}$ After 6 months of full-time work, I had not got beyond the first page. Trying to analyse underlying beliefs about beliefs about beliefs ..., and intentions on different levels, proved to be a bottomless pit. And it was one where empirical criteria for belief attribution - was that what the students had really believed? - were hard to find. I concluded that although the NTD model was a basis for generating human-machine dialogue, it was not, in all its elements, a basis for analysis of significant bodies of interaction corpus data. Thus, in my habilitation ${ }^{4}$ (Baker 2004) I argued that it is neither empirically possible nor theoretically relevant to attempt to determine students' beliefs 'underlying' their communicative actions in dialogue: dialogue is not a 'window on the mind', it is one significant manifestation of the (collective) mind in operation. What this means in methodological terms is that the group rather than individuals is taken as the unit of cognitive analysis, which focuses on the processes of co-elaboration of the discursive object. This can largely be done using the types of communicative acts and transformation operators described in the NTD paper.

\section{The Missing Strategy: Argumentation}

The research I have carried out on the processes of knowledge elaboration in and by argumentative interactions was inspired initially by the post-Piagetian theory of sociocognitive conflict (Doise et al. 1975). During the 1980s, conflicting results were obtained on the correlation between frequencies of conflicts (explicit disagreements) between students engaged in collaborative problem-solving, and learning outcomes (e.g., Blaye 1990). Although some researchers then abandoned the theory, others, amongst whom myself, followed the view of Mevarech and Light (1992), according to which cooperation and conflict should not in fact be strictly opposed (the latter presupposes some degree of the former); thus it may be the very processes by which verbal conflict is cooperatively resolved, by specific forms of argumentative interaction, that are important for learning. This led to the need to develop methods for analysing argumentative interactions that were specifically adapted to understanding knowledge co-elaboration processes.

Such methods could build on existing theories of argumentation (see van Eemeren et al. 1996, for an in-depth synthesis), but had to go beyond them, in that the object of interest was "arguing to learn" (Andriessen et al. 2003) rather than "learning to argue". Amongst the available theories of argumentation in the early 1990s, the one that had been most applied in education was that of Toulmin (1958). The theory is, however, essentially monological. I therefore took it as obvious that a dialogical theory of argumentation was most relevant to the task, which was to be found in the dialogic logic of Barth and Krabbe (1982).

\footnotetext{
${ }^{3}$ An anonymous reviewer of this paper raised the question as to why this analysis was thought to be necessary in the first place. Up to 1990, models for intentions in communication (Cohen et al. 1990) had been elaborated mostly on the basis of utterances, or short sequences of them, invented by the research for that purpose. The move to 'real' interaction data therefore seemed plausible and interesting to the author, at that period. It is of course possible to say, with hindsight, that the approach was too ambitious.

${ }^{4}$ In countries such as France and Germany, the habilitation is a further degree, to be conducted after the $\mathrm{PhD}$, as a requirement for becoming a full professor.
} 
Dialogic logic proposes a set of definitions of "avowed conflict situations", defined in terms of language users, concessions (propositions already commonly accepted) and one or more theses debated. It also proposes basic moves that can be made (e.g., direct defense, counter-active defense) and rules for the conduct of debates, both in terms of what moves can and must be made at a given stage of the discussion (e.g., all attacks must be defended, otherwise one loses the game; attacks may not be repeated) and in order to decide who has won the dialogical game (e.g., the player who has no more legal moves to make loses the game).

In order to try to understand how the playing of the argumentation dialogue game could lead to learning, I pursued the following basic conjecture: in terms of the NTD model, the "argue" and "refine" strategies are not mutually exclusive; they can and do occur simultaneously. In other terms, during argumentation dialogue, the meaning of key terms are negotiated, and compromise solutions can be mutually refined. This view fits with the notion of the multidimensionality of speech acts produced in dialogue (Bunt 1989). There is no such specific speech act as "argue" (van Eemeren and Grootendorst 1984) ${ }^{5}$; rather, an argument is an assertive, or even an interrogative or directive, which can take on, simultaneously, the communicative functions of "argument", given logico-semantic relations between its content and semantic contents asserted by the opponent, and of "refine", given that it proposes a new meaning for a previous argument.

In analysing multiple corpora of interactions between students in both collaborative problem-solving and pedagogical debate situations, I therefore pursued two directions of research. The first aimed to analyse how new meanings for key concepts underlying debates could be co-elaborated, focussing on phenomena such as argument by conceptual dissociation (e.g., Baker 1999, 2002a). Examples would be attempting to preserve a thesis by proposing to dissociate the concept "friction" acting on a falling body into "air friction" and "loss on impact with the ground", which would enable both protagonists to be 'right' (or, conversely, associating both of the latter within the general concept of friction). Or again, in a debate about the acceptability of geneticallymodified organisms, there is often an underlying process of "refinement", or negotiation of the meaning of the concept "Nature".

The second research direction aimed to understand the relations between the outcomes of a debate (e.g., refutation, successful defense, compromise, avoidance) and changes in participants' views (beliefs, commitments, opinions, acceptances). The method used was to design Computer-Supported Collaborative Learning (CSCL) communication interfaces (see below) that required students to express their degrees of belief in specific elements of their individual problem solutions (usually texts), before and after debating (e.g., De Vries et al. 2002; Baker 2003, 2009). Changes in students' views following debate could then be correlated with characteristics of the argumentative interaction, as a means of identifying the interactive processes responsible for individual cognitive change.

The results that emerged (see e.g., Baker 2003, 2009) were clearly differentiated with respect to scientific domains, such as mathematics and physics, and socioscientific domains such as history or geography (involving questions such as the acceptability of nuclear energy, or genetically-modified organisms). In the former case (scientific), on the basis of their argumentative interactions, students' viewpoints tend

\footnotetext{
5 These authors describe the term "argument" as referring to a "constellation" of speech acts.
} 
to change towards weakening of attitudes, (for example, from "I'm sure" to "I'm not sure" and "I'm sure it's wrong"). This can be explained by the fact that students have no prior highly elaborated ideological systems with respect to physics; and since their knowledge is undergoing co-elaboration in the learning situation, the most understandable strategy would seem to be: "there must be something wrong with the idea, since we argued about it; it can't be that; let it drop". In socio-scientific domains, however, ideological systems of beliefs and values can collide (for example "ecology" versus "scientific progress" ideologies); and in this case students' viewpoints can polarise, each further elaborating their own opposed views as a result of the debate (which is, in a sense, a type of cognitive progress).

In the continuation of this research, I have proposed that in order to understand "arguing to learn" (Andriessen et al. 2003) rather than "learning to argue", it is necessary to go beyond consideration of pragma-dialectics (van Eemeren and Grootendorst 1984) and epistemic/conceptual transformations, to consider discourse genres circulating in dialogue (cf. Baker et al. 2012), but also the nature of the interpersonal relation and the interactive circulation of affect (see below).

\section{Affective Learning Together}

As is common experience, trying to resolve conflicts of opinion by argumentation dialogue is usually a process that is highly charged with affects. In the case where affects are negative, this may threaten friendship relations. Muntig and Turnbull (1998) showed experimentally that one cannot explain the way that an argumentation dialogue unfolds without recourse to emotion, since the degree of perceived aggressiveness of a criticism determines the argumentation strategy that will be used (attack the attack, or defend one's thesis). The more a critique is perceived as threatening to a person's self esteem, the more negative emotions will be experienced (such as anger, disappointment) and the more it is likely that receivers of critiques will directly defend their theses and thereby 'themselves'.

In collaboration with Jerry Andriessen (Andriessen et al. 2011, 2013), I realised that the notion of "tension-relaxation", present in the early work of Bales (1950), had never really been fully exploited, in formal terms. Bales proposed that social interactions could be divided into a "task" zone and a "socio-emotional" zone, the latter being concerned with regulation of tensions between people. Drawing on a broad literature, in dialogue and argumentation theory, we extended this concept towards a formal analysis method. Our aim was to study the 'interaction' between deepening of a conflict (extending down into an argument chain) and fluctuations in tension-relaxation. The expectation was that deepening conflicts would lead to rise in tension, up to a threshold that could be supported by the interpersonal relation. Some early results showed that there was a lag in the lowering of tension after a local conflict, which could then make tension levels for subsequent conflicts higher than they might have needed to be. We also were led to elaborate the notion of a "collaborative working relation", which develops over time (Andriessen et al. 2013) and acts as a 'buffer', or a mediating mechanism, to the mutual regulation of tensions.

Although the importance of emotion in (individual) learning has already been emphasised in artificial intelligence research (Picard et al. 2004), in the field of collaborative learning, it is only very recently that research has turned its attention 
towards a systematic analysis of interpersonal relations and affects, as they play out in interaction. A first collection of articles on this theme was published in 2013 (Baker et al. 2013), following an international workshop financed by the European Science Foundation.

\section{Designing Computer-Supported Collaborative Learning Interfaces}

I have already alluded to research on designing CSCL interfaces above, in discussing argumentation in negotiative dialogue (see Scheuer, et al. 2010, for a review of research on argumentation in CSCL). After the publication of the NTD paper, in collaboration with several colleagues (Kristine Lund, Matthieu Quignard, Arnauld Séjourné, Gaëlle Molinari) I applied what was originally a human-machine dialogue model to the design of structured communication interfaces in CSCL environments. For example, in Baker and Lund (1997), we were the first in that field (cf. Winograd 1988, in the field of computer-supported cooperative work) to design and experiment interfaces that structured communication in terms of "buttons" corresponding to the speech acts of negotiative dialogue. We showed that communication that was structured in this way led to the emergence of a broader set of forms of cooperation (Baker 2002b) than with an unstructured interface. More generally, in comparison with face-to-face interactions for the same (physics problem-solving task), use of the free communication (CHAT) interface led the students to eliminate verbiage and to focus on more complex aspects of the task (Tiberghien and de Vries 1997).

By way of illustration (and perhaps also to try to whet the appetites of researchers working on automatic interaction analysis), Table 1 reproduces an extract from a "free CHAT" interaction, and Table 2 an extract from an interaction produced with the "structured" communication interface (Baker and Lund 1997). The examples are both taken from the beginning of interactions and were selected in order to preserve meaningful complete exchanges. Therefore, the extract in Table 1 is of a longer duration, i.e., $603 \mathrm{~s}$, than that shown in Table 2, of 484 s' duration. In both cases, the students (16-17 years old) communicate only at a distance (by Intranet) using the interfaces, two in number in each case, one for communication and another for creating diagrams called "energy chains" (Tiberghien and Megalakaki 1995). All interactions were traced automatically, and are here translated from the original French whilst preserving typographical mistakes; the students' names have been changed. In Table 2, column 4 ("Dialogue"), text between "[]" indicates that the students clicked on the button having this name; text in italics following such button traces corresponds to text that has been freely typed by the students. Time is measured, in seconds, from the opening of the session with the interfaces (which does not necessary correspond to when the students begin to work on them), and is automatically recorded either once the student presses "return" to send a message, or else once an action is initiated on the graphical interface for creating energy chain diagrams.

As stated above, the interaction extracts are not of the same length, the second being considerably shorter than the first. But notwithstanding this fact, in this shorter duration, the structured interaction comprises around twice as many communicative acts as the free interaction (17 in comparison with 8). The situation is inversed with respect to graphical actions ( 5 for the free interface, only 2 in the structured interaction example). Over the whole corpus, the structured interactions were more fluid in this respect and more 
Table 1 Extract from a free-CHAT interaction (energy chain task)

\begin{tabular}{|c|c|c|c|c|}
\hline$N$ & $\mathrm{~T}(\mathrm{sec})$ & Student & Dialogue & Graphical actions \\
\hline 1 & 225 & Catherine & & reservoir created: reservoir1 \\
\hline 2 & 257 & Anne & & $\begin{array}{l}\text { Transformer created: transfo1 } \\
\text { Link created: link1, transfo1 to } \\
\text { reservoir1 } \\
\text { Deleted: link1 }\end{array}$ \\
\hline 3 & 451 & Catherine & i'll do the transfer & \\
\hline 4 & 482 & Anne & and me & \\
\hline 5 & 527 & Catherine & you the second resvroir & \\
\hline 6 & 564 & Anne & ok go ahead & \\
\hline 7 & 594 & Catherine & & $\begin{array}{l}\text { Link created: link2, reservoir1 } \\
\text { to transfo1 }\end{array}$ \\
\hline 8 & 617 & Catherine & over to you & \\
\hline 9 & 707 & Anne & $\begin{array}{l}\text { but you have to begin by a reservoir } \\
\text { and end with a reservoir }\end{array}$ & \\
\hline 10 & 803 & Catherine & $\begin{array}{l}\text { i began with a reservoir then by a } \\
\text { transformer now we have to put a } \\
\text { reservoir ok }\end{array}$ & \\
\hline 11 & 828 & Anne & ok & \\
\hline
\end{tabular}

importantly, as stated above, more symmetrical in terms of the students' participation. By contrast, the free-CHAT interactions were mostly characterised by an asymmetrical form of cooperation that was based on sharing out responsibility for either drawing the diagram or else commenting, of the type "you do the diagram, I'll tell you if I don't agree". Perhaps more importantly, with respect to learning potential, the free-CHAT interactions are largely operational — the students mostly just 'do the task' - whereas the structured interactions include more discussion and explanation concerning the meaning of the task itself (which was the reason why buttons were included for "[Why?]" and "[Because...]"). It should be noted that there were no differences in the quality and correctness of students' final energy chain diagrams.

Finally, on this issue, it is perhaps possible and relevant in a commentary article of this type to report informal observations made by researchers during the experiments themselves, which are usually precluded in classical research articles. At the end of the session/lesson of around one and a half hours' duration, the teacher had difficulty in stopping the students who were using the structured interface, whereas, according to the teacher, this was certainly not usually the case with regular physics lessons. Apparently, the students had become immersed in the interface, and were using it to play a type of fun game, involving each trying to click on communicative act buttons more quickly than the other.

In part initiated by this relatively early work, an active contemporary sub-field of CSCL research is concerned with devising means for "scripting" collaboration (Fischer et al. 2006). The basic problem here is to script the interaction in order to favour productive collaboration processes, whilst at the same time not stifling creativity (Dillenbourg 2002). Scripting can be applied in different ways. In addition to scripting 
Table 2 Extract from a "structured"-CHAT interaction (energy chain task)

\begin{tabular}{|c|c|c|c|c|}
\hline$N$ & $\mathrm{~T}(\mathrm{sec})$ & Student & Dialogue & Graphical actions \\
\hline 1 & 56 & Roland & [Read the docs] & \\
\hline 2 & 95 & Roland & [Where do we begin?] & \\
\hline 3 & 121 & Marie & [I propose to...][Create a reservoir] & \\
\hline 4 & 144 & Roland & [Which one?] & \\
\hline 5 & 179 & Roland & {$[\mathrm{Hi} !]$} & \\
\hline 6 & 200 & Marie & [I don't know $]$ & \\
\hline 7 & 213 & Roland & [I think that...] the first res is called battery & \\
\hline 8 & 262 & Roland & [Do you agree?] & \\
\hline 9 & 287 & Marie & [Agreed] & \\
\hline 10 & 312 & & & reservoir created: reservoir 1 \\
\hline 11 & 334 & & & named: reservoir1, battery \\
\hline 12 & 357 & Roland & [What shall we do ?] & \\
\hline 13 & 376 & Marie & [I propose to...] $[$ Create a reservoir $]$ & \\
\hline 14 & 397 & Roland & [I don't agree $]$ & \\
\hline 15 & 412 & Roland & [I propose to...][Create a transformer $]$ & \\
\hline 16 & 432 & Roland & [Do you agree?] & \\
\hline 17 & 457 & Marie & [Why?] & \\
\hline 18 & 472 & Roland & $\begin{array}{l}\text { [I think that...] the bulb is a transformer } \\
\text { of electrical energy }\end{array}$ & \\
\hline 19 & 540 & Marie & [Agreed] & \\
\hline
\end{tabular}

communicative acts, as mentioned above, probably the most fundamental way of scripting is to structure sequences of learning tasks in terms of successive phases. For example, although it is quite possible for students to solve problems together and to reflect on their foundations in face-to-face interactions, this may be more difficult at a distance, given characteristics of some CMC interfaces that exclude parallel action. Providing a separate reflexion phase, subsequent to joint problem-solving, may therefore be beneficial (cf. De Vries et al. 2002). A third means of scripting collaboration could be termed "semiotic", since it concerns the means by which the task is expressed. The work of Suthers and colleagues, on the Belvédère system (Suthers et al. 1997) was the initiator of much subsequent work on use of argument or "evidence" diagrams in CSCL research. I also continued this line of investigation by structuring argumentation dialogue in CSCL using specifically designed interfaces for co-creating argument diagrams (e.g., Baker et al. 2003). Perhaps unsurprisingly, we discovered that the learning effects of particular semiotically-structured tools for joint argumentation depended on the precise way in which the learners' task was structured. For example, within a given task duration (around $1 \mathrm{~h}$ ), it is more beneficial for argumentation-based collaborative learning to first ask students to debate 'freely' (with a CHAT), then to reanalyse their own debate in the form of a diagram, than to allow students to discuss and co-create argument diagrams concurrently (Lund et al. 2007).

In sum, structured CSCL interfaces, provided they are structured appropriately, can have advantages for learners, educators and researchers. For learners, interfaces can be 
provided that are, hopefully, both fun to use and that channel their efforts in the right direction. For educators, the fact that students' interactions can be automatically traced facilitates their evaluation, provided that automatic tools for this are available. For researchers, structured communication interfaces provide a means for psychologists to experiment with the form of the interaction itself, and, for researchers in computer science, the fact that the students' actions are already partially pre-categorised paves the way for automatic analysis (see International Journal of Artificial Intelligence in Education, 24, 1, 2014). An important recent approach to qualitative, quantitative and formal analysis of group interactions is based on the notion of "productive multivocality" (Suthers et al. 2013), whereby multiple analytical frameworks are confronted in a constructive way. With respect to the old alliance of cognitive psychology and artificial intelligence referred to above, based on the shared symbolic information processing model, the productive multivocality approach, emerging almost 30 years later, can be seen as a new alliance between research on learning analytics in AIED and the diverse theoretical approaches to be found in the areas of CSCL and the Learning Sciences.

Finally, we should of course be wary of technological determinism: the designers' intentions with respect to a structured CSCL communication interface will not necessarily determine how student users actually use or appropriate it (cf. Overdijk et al. 2012). In the research cited above (Baker and Lund 1997), we observed a case of just such an idiosyncratic joint appropriation of the communication tool. The designers had provided a "beep" button, whose intended use was for students to be able to attract the attention of others (important in distance communication without awareness tools). In fact, the students explicitly negotiated their own way of using this functionality, as a signal that they were going to change between task and communication windows. This means that automatic analysis of pre-structured communication will need to understand the students' actions in their interactive context.

\section{Extending to other Epistemic Domains: Explanation, Co-design and Creativity}

Over the past 10 years I realised that the knowledge co-elaboration processes described in the NTD model were not specific to educational situations, but rather could occur in any "epistemic situation", i.e., where it is necessary, in order to carry out a task, to elaborate new knowledge, in everyday life and especially at work. I therefore extended the application of the model to problems of (negotiated) explanation generation in human-machine dialogues (e.g., Baker et al. 1996) and to co-design situations. In the former case, I realised that negotiation, argumentation and explanation were intimately linked (Baker 2000): one may need to argue for explanations, to explain in arguing, and in both cases to negotiate meaning. In the case of co-design situations, we developed a general multi-dimensional metric for appraisal of the "quality of collaboration" (Détienne et al. 2012a). With colleagues, I have also applied an integrated model of negotiation and argumentation to the analysis of discussions in online epistemic communities, such as Wikipedia (Détienne et al. 2012b).

Therefore, today I consider that the research problem that an extended and deepened NTD model addresses is that of understanding the processes of negotiation of meaning in epistemic situations, i.e., the title of the present paper. The term "negotiation of meaning" has a long history in research on interactional linguistics (e.g., Edmondson 
1981). However, in research on Computer-Supported Collaborative Learning (CSCL), notably at the instigation of T. Koschmann (e.g., Koschmann 1996), the preferred expression has become "meaning-making". Indeed, many researchers consider that the emphasis on qualitative analysis of the processes of meaning-making defines the field of CSCL, and possibly even the Learning Sciences (Sawyer 2014).

\section{Concluding Remarks}

Over the previous 20 years, I have deepened and extended the model of negotiative dialogue presented in Baker (1994). I have deepened it notably in terms of further specification of the argumentation strategy, and extended it in two ways: firstly, by taking into consideration other dimensions of dialogue, such as interpersonal relations and emotions, and secondly, by extending the application of the model towards other epistemic problems and situations, such as CSCL communication interfaces, explanation generation, co-design, creativity and discussions in online epistemic communities. The basic core of the model remains essentially the same, in an extended form. The underlying theory, however, has been radically changed, from a cognitivist model of thoughts underlying dialogue, to a view of dialogue itself as one manifestation of collective thinking (Allwood 1997).

Looking forward, I see many unresolved problems in the analysis and modelling of epistemic dialogues. The most important problems, as I see them, concern firstly, how to formalise the nature of interpersonal relationships (beyond simple categories such as "friendship") as they are played out and fluctuate in dialogues, in relation to processes of interactive regulation of affects and knowledge co-elaboration. Secondly, it is necessary to gain better understanding of how to analyse the way in which students' everyday discourse genres (including those relating to information and communication technologies, such as "sms-ese"), anchored in their social backgrounds, impinge on their appropriation of schoolrelated genres (Wertsch 1991; see also Baker et al. 2012). In the context of the design and implementation of systems for guiding groups of online learners, these problems could present interesting challenges for Artificial Intelligence and Education research.

Acknowledgments My first recognition goes to the people 'around' me, when I first entered into this line of research. They were, on the closest level (and in no particular order): Mark Elsom-Cook, Fiona Spensley, Claire O'Malley, Pat Fung, Rod Moyse, Ann Blandford, John Domingue, and many more. A little further away, but nevertheless very influential on this research, were Tim O’Shea, John Self, Gordon McCalla, Jim Greer, Paul Brna, Brigitte Safar and Pierre Dillenbourg. In the intervening decades, the list of colleagues who have helped me to shape these research directions, either by direct collaboration or else by the inspiration of their work, is very long: my apologies in advance for any almost unforgivable omissions. Thanks to: Andrée Tiberghien, Jens Allwood, Christian Plantin, Kristine Lund, Matthieu Quignard, Arnauld Séjourné, FrançoisXavier Bernard, Annie Corbel, Jean-Jacques Girardot, and Françoise Détienne. I would like to thank the reviewers of this paper, as well as the special issue editors, for their very helpful critical remarks.

\section{References}

Allwood, J. (1997). Dialog as collective thinking. In P. Pylkkänen, P. Pylkkö, \& A. Hautamäki (Eds.), Brain, Mind and Physics (pp. 11-24). Amsterdam: Ios Press. 
Andriessen, J., Baker, M. J., \& Suthers, D. (2003). Arguing to Learn: Confronting Cognitions in ComputerSupported Collaborative Learning environments. Dordrecht: Kluwer Academic Publishers.

Andriessen, J., Baker, M., \& van der Puil, C. (2011). Socio-cognitive tension in collaborative working relations. In S. Ludvigsen, A. Lund, I. Rasmussen, \& R. Saljo (Eds.), Learning across sites: new tools, infrastructures and practices (pp. 222-242). London: Routledge.

Andriessen, J., Pardijs, M., \& Baker, M. J. (2013). Getting on and getting along: tension in the development of collaborations. In M. J. Baker, J. Andriessen, \& S. Järvelä (Eds.), Affective Learning Together: social and emotional dimensions of collaborative learning (pp. 205-230). London: Routledge.

Baker, M. J. (1989a). An artificial intelligence approach to musical grouping analysis. Contemporary Music Review, 3(1), 43-68.

Baker, M. J. (1989b). Negotiated Tutoring: An Approach to Interaction in Intelligent Tutoring Systems. PhD thesis in cognitive science (unpublished), Institute of Educational Technology, The Open University (UK).

Baker, M. J. (1993). Dialogic Learning: Negotiation and Argumentation as Mediating Mechanisms. Proceedings of AI-ED '93: World Conference on Artificial Intelligence in Education, August 1993, Edinburgh (GB).

Baker, M. J. (1994). A Model for Negotiation in Teaching-Learning Dialogues. International Journal of Artificial Intelligence in Education, 5(2), 199-254.

Baker, M. J. (1999). Argumentation and Constructive Interaction. In G. Rijlaarsdam \& E. Espéret (Series Eds.) \& Pierre Coirier and Jerry Andriessen (Vol. Eds.) Studies in Writing: Vol. 5. Foundations of Argumentative Text Processing, 179 - 202. Amsterdam: University of Amsterdam Press.

Baker, M. J. (2000). Explication, Argumentation et Négociation : analyse d'un corpus de dialogues en langue naturelle écrite dans le domaine de la medicine [Explanation, Argumentation and Negotiation: analysis of a natural language dialogue corpus in the domain of medicine]. Psychologie de l'Interaction, 9-10, 179210.

Baker, M. J. (2002a). Argumentative interactions, discursive operations and learning to model in science. In P. Brna, M. Baker, K. Stenning, \& A. Tiberghien (Eds.), The Role of Communication in Learning to Model (pp. 303-324). Mahwah: Lawrence Erlbaum Associates.

Baker, M. J. (2002b). Forms of cooperation in dyadic problem-solving. Revue d'Intelligence Artificielle, $16(4$ 5), 587-620.

Baker, M. J. (2003). Computer-mediated Argumentative interactions for the co-elaboration of scientific notions. In J. Andriessen, M. J. Baker, \& D. Suthers (Eds.), Arguing to Learn: Confronting Cognitions in Computer-Supported Collaborative Learning environments (pp. 47-78). Dordrecht: Kluwer Academic Publishers.

Baker, M. J. (2004). Recherches sur l'élaboration de connaissances dans le dialogue [Research on elaboration of knowledge in dialogue]. Habilitation in psychology, Université Nancy 2. https://tel.archives-ouvertes. fr/tel-00110314/file/hdr.pdf.

Baker, M. J. (2009). Intersubjective and intrasubjective rationalities in pedagogical debates: Realizing what one thinks. In B. Schwarz, T. Dreyfus, \& R. Hershkowitz (Eds.), Transformation of Knowledge Through Classroom Interaction (pp. 145-158). London: Routledge.

Baker, M. J., \& Lund, K. (1997). Promoting reflective interactions in a computer-supported collaborative learning environment. Journal of Computer Assisted Learning, 13, 175-193.

Baker M. J., Charnay L., Joab M., Lemaire, B., Safar, B., Schlienger, D. (1996). Incorporating Functionalities of Expert Medical Critiquing Dialogues in the Design of a Graphical Interface. Proceedings of 8th IEEE International Conference on Tools with Artificial Intelligence (ICTAI'96), Toulouse, 1996

Baker, M. J., Quignard, M., Lund, K., \& Séjourné, A. (2003). Computer-supported collaborative learning in the space of debate. In B. Wasson, S. Ludvigsen, \& U. Hoppe (Eds.), Designing for Change in Networked Learning Environments: Proceedings of the International Conference on Computer Support for Collaborative Learning 2003 (pp. 11-20). Dordrecht: Kluwer Academic Publishers.

Baker, M. J., Bernard, F.-X., \& Dumez-Féroc, I. (2012). Integrating computer-supported collaborative learning into the classroom: the anatomy of a failure. Journal of Computer Assisted Learning, 28, 161-176.

Baker, M. J., Andriessen, J., \& Järvelä, S. (Eds.). (2013). Affective Learning Together: social and emotional dimensions of collaborative learning. London: Routledge.

Bales, R. F. (1950). A set of categories for the analysis of small group interaction. American Sociological Review, 15, 257-263.

Barth, E. M., \& Krabbe, E. C. W. (1982). From Axiom to Dialogue: A philosophical study of logics and argumentation. Berlin: Walter de Gruyter.

Blaye, A. (1990). Peer interaction in solving a binary matrix problem: possible mechanisms causing individual progress. Learning and Instruction, 2, 45-56. 
Bunt, H. C. (1989). Information dialogues as communicative action in relation to partner modelling and information processing. In M. M. Taylor, F. Néel, \& D. G. Bouwhuis (Eds.), The structure of multimodal dialogue (pp. 47-74). Netherlands: Elsevier Sciences Publishers.

Cohen, L. J. (1992). An Essay on Belief and Acceptance. Oxford: Clarendon.

Cohen, J., Morgan, J., \& Pollack, M. (1990). Intentions in Communication. Cambridge: MIT Press.

Collins, A. \& Grignetti, M.C. (1975). Intelligent CAI. BBN Report Number 3181. Downloaded from the Internet on 19 October 2014, from: http://files.eric.ed.gov/fulltext/ED114089.pdf.

De Vries, E., Lund, K., \& Baker, M. J. (2002). Computer-mediated epistemic dialogue: explanation and argumentation as vehicles for understanding scientific notions. The Journal of the Learning Sciences, 11(1), 63-103.

Détienne, F., Baker, M., \& Burkhardt, J.-M. (2012a). Quality of collaboration in design meetings: methodological reflexions. CoDesign: International Journal of CoCreation in Design, 8(4), 247-261.

Détienne, F., Barcellini, F., Baker, M., Burkhardt, J.-M., \& Fréard, F. (2012b). Online epistemic communities: theoretical and methodological directions for understanding knowledge co-elaboration in new digital spaces. Work: A Journal of Prevention, Assessment and Rehabilitation, 41(1), 3511-3518.

Dillenbourg, P. (2002). Over-scripting CSCL: The risks of blending collaborative learning with instructional design. In P. A. Kirschner (Ed.), Three worlds of CSCL. Can we support CSCL? (pp. 61-91). Heerlen: Open Universiteit Nederland.

Doise, W., Mugny, G., \& Perret-Clermont, A. N. (1975). Social interaction and cognitive development. European Journal of Social Psychology, 5, 367-383.

Edmondson, W. (1981). Spoken Discourse: A model for analysis. London: Longman.

Edwards, D. (1993). But what Do children really think?: discourse analysis and conceptual content in children's talk. Cognition and Instruction, 11(3 \& 4), 207-225.

Fischer, F., Kollar, I., Mandl, H., \& Haake, J. M. (Eds.). (2006). Scripting Computer-Supported Collaborative Learning Cognitive, Computational and Educational Perspectives. Berlin: Springer.

Hoppe, H. U. (1995). The Use of Multiple Student Modeling to Parametrize Group Learning (The Proceedings of Artificial Intelligence in Education, pp. 234-249). Washington, D.C: AACE Publications.

Koschmann, T. (Ed.). (1996). CSCL: Theory and Practice of an Emerging Paradigm. Mahwah: Lawrence Erlbaum Associates.

Lund, K., Molinari, G., Séjourné, A., \& Baker, M. (2007). How do argumentation diagrams compare when student pairs use them as a means for debate or as a way for representing their debate? International Journal of Computer Supported Collaborative Learning, 2, 273-295.

Mephu-Nguifo, E., Baker, M. J., \& Dillenbourg, P. (1999). Knowledge Transformations in Agents and Interactions: A comparison of Machine Learning and Dialogue Operators. In P. Dillenbourg (Ed.), Collaborative Learning: Cognitive and Computational Approaches (pp. 122-146). Amsterdam: Pergamon / Elsevier Science.

Mevarech, Z. R., \& Light, P. H. (1992). Peer-based interaction at the computer: looking backward, looking forward. Learning and Instruction, 2, 275-280.

Michalski, R. S. (1993). Inferential theory of learning as a conceptual basis for multistrategy learning. Machine Learning, 11(2-3), 111-151.

Moyse, R., \& Elsom-Cook, M. (Eds.). (1992). Knowledge Negotiation. London: Academic.

Muntig, P., \& Turnbull, W. (1998). Conversational structure and facework in arguing. Journal of Pragmatics, $29,225-256$.

Overdijk, M., van Diggelen, W., Kirschner, P., \& Baker, M. (2012). Connecting agents and artifacts in CSCL: towards a rationale of mutual shaping. International Journal of Computer Supported Collaborative Learning, 7(2), 193-210.

Picard, R. W., Papert, S., Bender, W., Blumberg, B., Breazel, C., Cavallo, D., Machover, T., Resnick, M., Roy, D., \& Strohecker, C. (2004). Affective learning — a manifesto. BT Technology Journal, 22(4), 253-269.

Sawyer, K. (Ed.). (2014). The Cambridge Handbook of The Learning Sciences (2nd ed.). New York: Cambridge University Press.

Scheuer, O., Loll, F., Pinkwart, N., \& McLaren, B. (2010). Computer-supported argumentation: a review of the state of the art. International Journal of Computer-Supported Collaborative Learning, 5(1), 43-102.

Self, J. (1992). Computational Mathetics: the missing link in Intelligent Tutoring Systems research? In E. Costa (Ed.), New Directions for Intelligent Tutoring Systems Research (pp. 38-56). Berlin: Springer.

Skinner, B. F. (1961). Teaching machines. Scientific American, 205, 90-112.

Sleeman, D., \& Brown, J. S. (1982). Intelligent Tutoring Systems. London: Academic.

Suthers, D., Toth, E., and Weiner, A. (1997). An Integrated Approach to Implementing Collaborative Inquiry in the Classroom. Proceedings of the 2nd International Conference on Computer Supported Collaborative Learning (CSCL'97), Toronto, December 10-14, pp. 272-279. 
Suthers, D., Lund, K., Rosé, C. P., Teplovs, C., \& Law, N. (Eds.). (2013). Productive Multivocality in the Analysis of Group Interactions. New York: Springer.

Tiberghien, A., \& De Vries, E. (1997). Relating characteristics of learning situations to learner activities. Journal of Computer Assisted Learning, 13, 163-174.

Tiberghien, A., \& Megalakaki, O. (1995). Contribution to a characterisation of a modelling activity case of a first qualitative approach of energy concept. European Journal of Psychology of Education, X(4), 369383.

Toulmin, S. E. (1958). The Uses of Argument. Cambridge: Cambridge University Press.

Van Eemeren, F. H., \& Grootendorst, R. (1984). Speech Acts in Argumentative Discussions. DordrechtHolland: Foris Publications.

van Eemeren, F. H., Grootendorst, R., \& Henkemans, F. S. (1996). Fundamentals of Argumentation Theory: A Handbook of Historical Backgrounds and Contemporary Developments. Mahwah: Lawrence Erlbaum Associates.

Wertsch, J. V. (1991). Voices of the Mind. A Sociocultural Approach to Mediated Action. USA: Harvester Wheatsheaf.

Winograd, T. (1988). A language/action perspective on the design of cooperative work. Human Computer Interaction, 3, 3-30. 